Wenzel RP. Risk factors for hospital-acquired candidemia: a matched case-control study. Arch Intern Med 1989; 149:2349-53.

4.Sobel JD, Kauffman CA, McKinsey D, et al. Candiduria: a randomized, double-blind study of treatment with fluconazole and placebo. CID 2000;30:19-24.

\section{Pediatria \\ Qual É a ReCOMENDAÇÃo ATUAL PARA 0 TRATAMENTO DA TOXOPLASMOSE CONGÊNITA?}

A toxoplasmose congênita deve ser tratada com terapêutica específica em todos os recém-nascidos (RN) quer na forma sintomática ou subclínica, sendo neste último caso com a finalidade de prevenir as seqüelas tardias que possam ocorrer.

Os agentes que são recomendados para terapêutica específica são benéficos contra a forma de taquizoíto e nenhum medicamento tem se mostrado efetivo para erradicar a forma encistada do parasita, principalmente os cistos presentes no sistema nervoso central e olho.

As drogas utilizadas para o tratamento da toxoplasmose congênita no RN são: pirimetamina (daraprim $\left.{ }^{\circledR}\right)$; sulfadiazina; ácido folínico. A pirimetamina $\left(\right.$ daraprim $\left.^{\circledR}\right)$ é um substituto da fenilpirimidina, droga antimalárica, cuja vida média plasmática no RN e crianças menores de 18 meses de idade é de aproximadamente 60 horas. No líquido cefalorraquiano atinge $10 \%$ a $20 \%$ dos níveis séricos. Lembramos que o fenobarbital pode induzir a produção de enzimas hepáticas capazes de degradarem a pirimetamina, resultando em níveis séricos mais baixos com diminuição da sua vida média. A pirimetamina e sulfadiazina atuam sinergicamente contra o $T$. gondii com uma atividade combinada oito vezes maior do que se fossem utilizadas isoladamente. Outras sulfas podem também ser usadas, sendo tão efetivas quanto a sulfadiazina, como: a sulfapirazina, a sulfametazona e a sulfamerazina. $A$ pirimetamina inibe a dihidrofolato redutase, a qual é importante na síntese do ácido fólico, levando à depressão reversível e geralmente gradual da medula óssea. A neutropenia (reversível) constituia ação tóxica mais importante. Asuperdosagem acidental da pirimetamina em crianças pode resultar em vômitos, tremores, convulsões e depressão da medula óssea. A espiramicina, que anteriormente fazia parte do esquema terapêutico da toxoplasmose congênita no RN, não tem sido mais recomendada e tem falhado para prevenir a neurotoxoplasmose em pacientes imunodeprimidos e há ainda pouca informação em relação a sua eficácia no $\mathrm{RN}$ com toxoplasmose congênita, bem como a melhor dose e via de administração a serem utilizadas. Embora não apresente toxicidade hematológica, tem sido observado alterações do ECG, comprometimento hepático e/ou renal particularmente com o uso da droga injetável. Mais recentemente, a espiramicina é indicada apenas quando a gestante apresenta toxoplasmose como infecção ativa durante a gravidez, com a finalidade de reduzir a transmissão materno-fetal.

O esquema recomendado para tratamento da toxoplasmose congênita no RN é: pirimetamina (daraprim $\left.{ }^{\circledR}\right) 2 \mathrm{mg} / \mathrm{Kg} / \mathrm{dia}$, via oral, nos primeiros dois dias, seguido por $1 \mathrm{mg} / \mathrm{Kg} /$ dia por dois ou seis meses e, após, I mg/Kg/dia três vezes por semana; associada à sulfadiazina na dose de $100 \mathrm{mg} /$ $\mathrm{Kg} /$ dia, via oral, de I2/I2 horas; ácido folínico 10 a $20 \mathrm{mg} / \mathrm{dia}$, via oral, três vezes por semana (até completar um ano de tratamento). Corticosteróides têm sido recomendado naqueles RN com acometimento grave do SNC, quando a proteína líquórica for $\geq \mathrm{l} g / d$ l e quando houver coriorretinite em atividade. A dose preconizada de prednisona é de $1 \mathrm{mg} / \mathrm{Kg} / \mathrm{dia}$, via oral, $12 / 12$ horas, até redução da proteinorraquia e da coriorretinite. Todos os RN e crianças tratadas com pirimetamina devem realizar pelo menos um hemograma uma vez por semana, além da administração de ácido folínico na forma de leucovorin cálcico ${ }^{\circledR}$, com a finalidade de proteger a medula óssea dos seus efeitos tóxicos.

A prevenção da toxoplasmose congênita é de fundamental importância para um melhor controle da infecção evitando as graves seqüelas que podem ocorrer no feto e no RN.

\section{Edna M. de Albuquerque Diniz} Flávio Adolfo Costa Vaz

\section{Referências}

I. Diniz EMA. Infecções congênitas. Parte 2: Aspectos neonatais. In: Isfer EV, Sanchez RC, Saito M, editores. Medicina Fetal: diagnóstico pré-natal e conduta. Rio de Janeiro: Revinter; 1996. p. 545-80.

2. Remington JS, Mcleod R, Thulliez P, Desmonts G. Toxoplasmosis. In: Remington JS, Klein 10 , editors. Infectious diseases of the fetus and newborn infant. Philadelphia: W.B. Saunders; 200I. p. 205-346. 